\section{Global project under way to sample genetic diversity}

Washington. An international group of population geneticists, molecular biologists and anthropologists want to sample the world's population for genetic diversity — if they can find $\$ 25$ million to do the job properly.

The Human Genome Diversity Project hopes to use the diversity of living people to understand human evolution. The organizers say that the need is urgent because increasing urbanization threatens the integrity of small isolated populations on which this analysis depends. The information should also prove useful to the Human Genome Project, which does not consider population-level variation.

Ideally, the project would create thousands of cell lines from the nuclear DNA of sampled individuals. As a potentially permanent source of DNA, these lines could be used to answer questions about ancient migration patterns and the relative importance of selection and drift in divergent evolution as well as to improve understanding of the distribution of disease susceptibility or resistance.

The project must balance its desire for information against its limited resources. For example, the best sources of nuclear DNA, cell lines transformed by the use of blood samples, are also the most expensive and require laboratory procedures within 72 hours of sample collection. Although building new facilities and transferring technology are part of the general plan, where and how such laboratories can be built will limit the populations that can be sampled. The transformed cell lines. of information on diversity. Sardinia. organizers are also hoping that newer technology will provide cheaper and faster ways of obtaining data, such as using cheek swabs or hair follicles instead of blood to yield

Carrying out uniform DNA analysis, another priority for the project, may also require new technology if older data are to be made compatible with those collected using simpler markers and procedures. There are also ethical issues, including whether samples should be screened for pathogens such as HIV and how to prevent the misuse

The project, with a steering committee of five European and five US scientists and Luca Cavalli Sforza of Stanford University as chairman, has sponsored three workshops since last July to discuss sampling techniques, ethical issues and questions about funding. The committee hopes to present its recommendations at a fourth and final meeting next September in Alghero,

Population geneticists and statisticians in the first workshop set a lower limit of sampling at 25 unrelated individuals from 400 populations, recommending that 100 loci be analysed in describing the genome. At the second workshop, anthropologists compiled lists of priority populations for each region using groups called Isolates of Historical Interest (IHIs). These small populations are more likely to reflect direct descent from earlier small groups: only inbred groups differ from each other as a result of

\section{Italy tries to define basic research}

Munich. The Italian Ministry for Universities and Research has sent a scientific task force into its space agency ASI to sort out "as a matter of urgency" the continuing deadlock in the funding of basic space science. The experts have a month to decide how much of ASI's IL800 billion (US\$520 million) annual budget should go to fundamental research, resolving a prolonged and bitter feud between the agency and its scientific advisers that has blocked the flow of billions of lira to scientists.

Italy's scientific community initially welcomed the creation of ASI in 1988 to coordinate national space research. But continuing political infighting has hindered its work and led to much criticism of its conduct. Most damaging has been the disagreement about interpretation of the law requiring $A S I$ to spend at least 15 per cent of its budget on basic research. Ambiguous wording of the phrase led to different interpretations: ASI says that the Italian money spent by the European Space Agency (ESA) on construction of platforms should be included, while its scientific advisory committee believes that such spending is really applied. The difference amounts to billions of lira. The task force, which includes ESA president Francesco Carassa, has been asked to decide the question.

The dispute has delayed funding by several months and has opened up serious rifts within the advisory committee, which approves grant applications. The committee last September voted out its chairman, Remo Ruffini, who refused to approve any funds until the issue was resolved. Despite its sympathy to the cause, the committee felt that this unilateral action was detrimental to Italian research. But science minister Antonio Ruberti sided with Ruffini and the committee has not met since then.

Alison Abbott divergent evolution. As individuals mix with those in urban centres, evolutionary data are lost. Target populations were also picked to represent all major language groups.

The organizers have prepared a tentative aggregated list of priority populations including both IHIs and their nearest neighbours, which they hope to make public for comment. The list is not complete because all regions were not equally represented at the meeting and many scattered populations have already been sampled. For example, an international project to study the HLA locus has for 25 years been creating cell lines in 400 labs around the world.

Prospects for obtaining the estimated $\$ 25$ million needed over the next five years are uncertain. Meeting last week at the US National Institutes of Health (NIH), the committee talked to representatives from NIH, the National Science Foundation and the Department of Energy, who offered encouragement but no promise of funding. The group is also hoping to gain a place in a fiveyear plan being written now for the Human Genome Project.

Money is being sought in the next Framework programme of the European Communities for eleven laboratories to draw samples throughout the Middle East and Eastern Europe, and funding agencies in China, Japan and India have expressed support for sampling projects in their own countries. In the meantime, investigators are using money from existing grants for small-scale sampling.

Jenna Roberts

\section{Bart's loses fight against merger}

London. St Bartholomew's Hospital in London - known as Bart's - has reluctantly accepted the conclusions of a report commissioned by Britain's Department of Health that it should merge with the nearby Royal London Hospital (see Nature 361, 194; 1993).

Its decision came after the Health Minister, Virginia Bottomley, announced that she had accepted the report's conclusions that London's teaching hospitals must be merged because of declining demand for hospital services. But Bart's still hopes to retain its historic Smithfield site, which it has occupied for 900 years.

Bottomley also announced a reprieve for two smaller specialist hospitals, the Royal Marsden Cancer Hospital and the Royal Brompton National Heart and Lung Hospitals. Both had protested that their research activities could suffer if they were required to merge with the Charing Cross Hospital, as the report had suggested. Special reviews will now be carried out of facilities for treatment and research in six specialist areas in the capital. These reviews will be completed by the end of May.

David Dickson 